\title{
Genetic analysis of body weights of individually fed beef bulls in South Africa using random regression models
}

\author{
N.W. Selapa ${ }^{1,2}$, K.A. Nephawe ${ }^{3}$, A. Maiwashe ${ }^{1}$ and D. Norris ${ }^{2}$ \\ ${ }^{1}$ Animal Production Institute, Agricultural Research Council, \\ Irene, South Africa \\ ${ }^{2}$ Department of Animal Production, University of Limpopo, \\ Turfloop, South Africa \\ ${ }^{3}$ Limpopo Department of Agriculture, Polokwane, South Africa \\ Corresponding author: N.W. Selapa \\ E-mail: wselapa@arc.agric.za
}

Genet. Mol. Res. 11 (1): 271-276 (2012)

Received May 16, 2011

Accepted July 7, 2011

Published February 8, 2012

DOI http://dx.doi.org/10.4238/2012.February.8.2

\begin{abstract}
The aim of this study was to estimate genetic parameters for body weights of individually fed beef bulls measured at centralized testing stations in South Africa using random regression models. Weekly body weights of Bonsmara bulls $(\mathrm{N}=2919)$ tested between 1999 and 2003 were available for the analyses. The model included a fixed regression of the body weights on fourth-order orthogonal Legendre polynomials of the actual days on test $(7,14,21,28,35,42,49,56$, $63,70,77$, and 84) for starting age and contemporary group effects. Random regressions on fourth-order orthogonal Legendre polynomials of the actual days on test were included for additive genetic effects and additional uncorrelated random effects of the weaning-herd-year and the permanent environment of the animal. Residual effects were assumed to be independently distributed with heterogeneous variance for each
\end{abstract}


test day. Variance ratios for additive genetic, permanent environment and weaning-herd-year for weekly body weights at different test days ranged from 0.26 to $0.29,0.37$ to 0.44 and 0.26 to 0.34 , respectively. The weaning-herd-year was found to have a significant effect on the variation of body weights of bulls despite a 28-day adjustment period. Genetic correlations amongst body weights at different test days were high, ranging from 0.89 to 1.00 . Heritability estimates were comparable to literature using multivariate models. Therefore, random regression model could be applied in the genetic evaluation of body weight of individually fed beef bulls in South Africa.

Key words: Random regression; Performance tests; Beef cattle

\section{INTRODUCTION}

Measurements of feed intake, body weight and other traits (such as scrotum circumference, body measurements, functional appearance, and condition score) are recorded during the central tests of beef bulls (Phase C) in South Africa. Repeated measurements on an individual (e.g., body weight, feed intake, etc.) are called longitudinal data. For this type of data, the interest lies in genetic parameters that explain the shape of curves that describe such traits, as those parameters might provide information on whether and how desirable changes in the course of such trait can be achieved (Meyer, 1998a).

Traditionally, multiple-trait models have been used to analyze such traits thus correcting observations towards certain landmark ages (e.g., beginning and final body weight). Optionally, the trait observations may be averaged to a single value (e.g., average daily gain), which might be essential in explaining the individual variation throughout the test. However, a better way of dealing with traits that are measured repeatedly over time is by using random regression models. Random regression models allow fitting a set of random regression coefficients of time on measurements for each individual thereby properly accounting for individual variation over the course of the trajectory (Meyer, 1998a).

Random regression models have been applied in animal breeding research (Meyer, 1999, 2000; Nephawe, 2004). However, genetic parameters that describe the performance pattern for bulls at central performance testing stations under South African conditions are not available. The objective of this study was to estimate genetic parameters for weekly body weights (BWT) using random regression models (RRMs) on data of beef bulls participating in centralized testing stations in South Africa.

\section{MATERIAL AND METHODS}

Data on Bonsmara bulls were obtained from the South African National Beef Cattle Improvement Scheme (NBCIS) database. Data consisted of records for bulls that had undergone central performance testing, collected between 1999 and 2003. Body weights were collected every week after a 12-h overnight fast for 84 days spent on test, following a pre-test adjustment period of 28 days. Bulls were placed in pens with electronic gates, which allowed individual access to particular feeders. Bulls were fed on a pelleted ration containing 13.0 
MJ ME/kg dry matter and $13 \%$ protein. The ration composed of $39.8 \%$ maize, $11.9 \%$ wheat pollard, $7.5 \%$ cottonseed, $5 \%$ lucerne, $20.5 \%$ maize straws, $9 \%$ molasses, $0.5 \%$ urea, $3.4 \%$ hominy chop, $0.5 \%$ salt, $1.4 \%$ limestone ground, $0.3 \%$ monocalcium phosphate, and $0.2 \%$ vitamin-mineral premix, which included the rumen modifier rumensin (Archer and Bergh, 2000). Further details of the performance testing procedures are available in the Agricultural Research Council - NBCIS Guidelines (2007). Data were edited to remove records of outliers and from contemporary groups with less than three sires. A summary of the data set after editing is given in Table 1 .

\begin{tabular}{lc} 
Table 1. Summary of the data. \\
\hline Feature & Number \\
\hline Number of bulls & 2,919 \\
Number of records per bull & 12 \\
Total number of records & 35,028 \\
Number of animals in pedigree & 12,441 \\
Mean starting age (days) & 242 \\
Starting age range (days) & $161-308$ \\
Starting-age classes & 14 \\
Weaning-herd-year groups & 211 \\
Contemporary groups & 135 \\
Mean initial body weight (kg) & 273 \\
Mean final body weight (kg) & 402 \\
\hline
\end{tabular}

The contemporary group was defined as the concatenation of test year, test number and the testing center where the bulls were tested. The starting ages were grouped into 14 classes of tens (i.e., from 181 to $190=$ starting-age class 2 , from 191 to $200=$ starting-age class 3 , etc.). However, starting-age class 1 had the highest range of starting age, i.e., from 161-180, because few animals fell under that starting-age range. The weaning-herd-year (WHY) groups were formed by a concatenation of the herd of origin of a bull with the weaning year for each bull.

Data of BWT of bulls were analyzed using an RRM. The model included the fixed regression of body weights on fourth-order (cubic) orthogonal Legendre polynomials of the actual days $(7,14,21,28,35,42,49,56,63,70,77$, and 84$)$ on test for starting age group and contemporary group effects. Random regressions on fourth-order orthogonal polynomials of the actual days on test were included for the additive genetic effect of the animal and additional uncorrelated random effects of the WHY and the permanent environment of the animal. The model was similar to that of Schenkel et al. (2002), fitted for consecutive body weights of bulls tested in central evaluation stations in Ontario (Canada).

The effect of WHY on the post-weaning traits was investigated in several studies (Tong et al., 1986; Amal and Crow, 1987; Schenkel et al., 2004; Nephawe et al., 2006). The recommendation from these studies was that WHY must be included in the model for postweaning traits of bulls at central performance testing stations. Although a more traditional approach would be to fit the WHY as a fixed effect, the WHY on post-weaning weight was fitted as random in order to estimate its variance (Schenkel et al., 2002; Nephawe et al., 2006). The model can be represented as follows:

$$
w_{i j}=\sum_{p=0}^{n-1} b_{p} \varphi_{p}\left(d_{i j}\right)+\sum_{p=0}^{n-1} \alpha_{p} \varphi_{p}\left(d_{i j}\right)+\sum_{r=1}^{3} \sum_{p=0}^{n-1} \gamma_{r_{j}} \varphi_{p}\left(d_{i j}\right)+\varepsilon_{i j} \quad \text { (Equation 1) }
$$


where $w_{i j}$ is the $\mathrm{j}^{\text {th }}$ measurement of weekly body weight on the $\mathrm{i}^{\text {th }}$ bull, $b_{p}$ is the fixed regression coefficient for the contemporary group, $\alpha_{p}$ is the fixed regression coefficient for the starting age class, $\gamma_{r p}$ is the random regression coefficient for the $\mathrm{r}^{\text {th }}$ random effect (i.e., WHY, additive genetic or permanent environment), $d_{i j}$ is the standardized actual days on test at recording for which Legendre polynomials are defined, and $\varphi\left(d_{i j}\right)$ is the respective $\mathrm{p}^{\text {th }}$ Legendre polynomials. The $n$ denotes the order of fit (in this study, order $=4$ ) and $\varepsilon_{i j}$ represents the random residual effect, which was assumed to be independently distributed with heterogeneous variance for each measurement period on test (i.e., variance for days 7, 14, 21, 28, 35, 42, 49, 56, 63, 70, 77, and 84 on test). (Co)variance components were estimated using the DXMRR program by Meyer (1998b). The matrices for coefficients were estimated directly from the data by REML (Meyer and Hill, 1997) as covariance matrices of the corresponding random regression. The convergence of the covariance components was visually inspected by repeatedly fitting the estimated coefficient matrix values over iterations as starting values for estimation of (co)variance components.

\section{RESULTS}

The mean and standard deviations for body weights at each test day were calculated and mean values for BWT gradually increased (from 273 to $402 \mathrm{~kg}$ for test day 7 to test day 84 , respectively) and so did their respective standard deviations. This pattern was expected, as when the number of days on test increases the body weights for the bulls are also expected to increase.

Table 2 presents estimates of variances for additive genetic, permanent environment, WHY, and the residual for body weight, and their respective ratios at different days on test. The additive genetic variances increased throughout the test, starting at 194.8 at the beginning of the test and rising to 361.8 at the end of the test. The heritability estimates ranged from 0.28 at day 7 to 0.26 at day 49 and remained constant until the end of the test. These heritability estimates are comparable to estimates observed by Amal and Crow (1987) on Angus-Hereford bulls; however, the estimates for Charolais-Simmental bulls were high (i.e., ranging from 0.61 to 0.47 for starting weight and weight at day 140, respectively). Schenkel et al. (2002) reported higher estimates that ranged from 0.33 to 0.40 from day 0 to day 140 , respectively. The heritability estimates have shown a constant pattern with time as compared to estimates from Schenkel et al. (2002), which increased as the test progressed. Amal and Crow (1987) reported a similar pattern to that observed in the current study using a sire model on data for both Angus-Hereford and Charolais-Simmental bulls. Nephawe et al. (2006) using Bonsmara data fitting a multiple trait model, reported higher ADG heritability estimates $(0.34)$ than observed in this study.

The estimated variances and ratios for the permanent environment increased over time, ranging from 259.5 to 587.4 and from 0.37 to 0.43 , respectively. The ratios were similar to Schenkel et al. (2002), which ranged from 0.36 at the beginning of the test and reached a maximum of 0.41 at the end of the test. Variance estimates for the WHY also increased over time (from 236.3 to 355.2 ), but their respective ratios decreased over time, starting at 0.34 at the beginning of the test and dropping to 0.26 at the end of the test. Amal and Crow (1987) found a similar (0.33) effect for the WHY and suggested that part of the variation due to WHY in bull body weights might have been due to the age of dams. Simm et al. (1985) reported that 20 to $30 \%$ of the variation in bull weights between 200 and 400 days of age for bulls weaned at 168 days was due to the effect of the age of the dam. Meyer et al. (1993) reported that maternal effects might affect post-weaning weights during the test as a carry over from weaning 
weight. Schenkel et al. (2002) also observed the significant WHY effect (from 0.32 to 0.18 for the start and end of the test, respectively) on body weights of bulls on test. However, Schenkel et al. $(2002,2004)$ observed about $8 \%$ WHY effect and indicated that the dam effect was not important in the analysis for post-weaning performance on test. Schenkel et al. (2004) also indicated that the WHY variation observed in their study was more likely to be due to real pre-weaning environmental effects than other sources of variation such as genetic or maternal effects. Nephawe et al. (2006) evaluated the importance of the dam effect (accounting for both maternal additive and permanent environmental effects) on both weaning and post-weaning traits and found that the dam effect did not have an important contribution to post-weaning traits. Thus, the effect of WHY in the current study might be due to other pre-weaning environmental effects other than maternal effects.

\begin{tabular}{|c|c|c|c|c|c|c|c|c|}
\hline Test day & $\sigma_{a}^{2}$ & $h^{2}$ & $\sigma_{c}^{2}$ & $\mathrm{c}^{2}$ & $\sigma_{q}^{2}$ & $q^{2}$ & $\sigma_{\mathrm{e}}^{2}$ & $\mathrm{e}^{2}$ \\
\hline 7 & 194.80 & 0.28 & 259.54 & 0.37 & 236.29 & 0.34 & 4.71 & 0.007 \\
\hline 14 & 216.81 & 0.29 & 274.13 & 0.37 & 235.37 & 0.31 & 24.04 & 0.032 \\
\hline 21 & 235.68 & 0.29 & 302.82 & 0.38 & 241.66 & 0.30 & 27.99 & 0.034 \\
\hline 28 & 251.29 & 0.29 & 336.85 & 0.39 & 251.89 & 0.29 & 27.72 & 0.032 \\
\hline 35 & 264.03 & 0.28 & 373.01 & 0.40 & 264.67 & 0.28 & 30.54 & 0.033 \\
\hline 42 & 274.64 & 0.27 & 410.39 & 0.41 & 279.22 & 0.28 & 45.56 & 0.045 \\
\hline 49 & 284.03 & 0.26 & 448.20 & 0.42 & 294.65 & 0.28 & 45.10 & 0.042 \\
\hline 56 & 293.29 & 0.26 & 484.75 & 0.44 & 309.70 & 0.28 & 27.76 & 0.024 \\
\hline 63 & 303.73 & 0.26 & 517.48 & 0.44 & 322.97 & 0.28 & 30.30 & 0.025 \\
\hline 70 & 317.00 & 0.26 & 544.21 & 0.44 & 333.69 & 0.27 & 42.32 & 0.034 \\
\hline 77 & 335.33 & 0.26 & 565.34 & 0.44 & 342.91 & 0.27 & 28.62 & 0.022 \\
\hline 84 & 361.82 & 0.26 & 587.35 & 0.43 & 355.22 & 0.26 & 77.27 & 0.056 \\
\hline
\end{tabular}

$\sigma_{\mathrm{a}}^{2}, \sigma_{\mathrm{c}}^{2}, \sigma_{\mathrm{q}}^{2}$, and $\sigma_{\mathrm{e}}^{2}=$ estimates of variances for additive genetic, permanent environment, weaning-herd-year, and for the residual, respectively. $\mathrm{h}^{2}, \mathrm{c}^{2}, \mathrm{q}^{2}$, and $\mathrm{e}^{2}=$ ratios for additive genetic, permanent environment, weaning-herdyear, and for the residual, respectively.

Heterogeneous variances were fitted for the temporary environmental effect for each test day. Estimates of variance for the temporary environmental effects fluctuated throughout the test and their corresponding ratios were very low as they contributed less than $5 \%$ of the total variance of the weekly body weights of bulls on test.

The covariances due to the permanent environment were always higher than those due to additive and WHY effects. In general, the covariance estimates for all effects between adjacent days exhibited an increasing pattern as animals aged. The additive genetic, permanent environment, WHY, and phenotypic (co)variance estimates ranged from 195 to 362,260 to 587, 236 to 355, and 695 to 1382, respectively. Nephawe (2004) and Arango et al. (2004) also reported the increasing pattern for genetic (co)variances when applying RRM to the genetic evaluation of cow weights in beef cattle.

The estimates of additive genetic correlation tended to decline as the difference in days increased. Additive genetic correlation estimates were always higher than the correlation estimates for the permanent and WHY effects and were more than 0.88 for any pair of days on test. Maximum correlation estimates closer to 1.00 between ages for the permanent environment, WHY and phenotypic effects were observed and the minimum values were $0.76,0.83$ and 0.78 for the permanent environment, WHY and phenotypic effects, respectively. In general, correlation estimates for all effects decreased as the interval between days on test increased. 


\section{DISCUSSIONS}

Body weights of individually fed beef bulls were analyzed using RRMs. The trajectory for both the genetic and environmental parameters was studied over the test period. Total additive variance increased throughout the test but heritability estimates were constant for several days on test. Heritability estimates for weekly weights were comparable to literature estimates. Weaning-herd-year had a considerable contribution to the variation of weekly body weights of bulls undergoing performance tests, despite the pre-adjustment period. Random regression models could be useful for the National Genetic Evaluation of body weights of South African beef bulls.

\section{ACKNOWLEDGMENTS}

The authors would like to thank the Animal Breeding and Genetics Section of the Agricultural Research Council-Animal Production Institute of South Africa for its resources and the Bonsmara Society and Technology for Human Resource for Industry Programme (THRIP) of the National Research Foundation (NRF) for supporting the research project.

\section{REFERENCES}

Agricultural Research Council (2007). National Beef Cattle Improvement Scheme (NBCIS): Guidelines. Version 1, 01. Animal Production Institute. Livestock Business Division, Irene.

Amal S and Crow GH (1987). Herd of origin effects on the performance of station-tested beef bulls. Can. J. Anim. Sci. 67: 349-358.

Arango JA, Cundiff LV and Van Vleck LD (2004). Covariance functions and random regression models for cow weight in beef cattle. J. Anim. Sci. 82: 54-67.

Archer JA and Bergh L (2000). Duration of performance tests for growth rate, feed intake and feed efficiency in four biological types of beef cattle. Livest. Prod. Sci. 65: 47-55.

Meyer K (1998a). Estimating covariance functions for longitudinal data using a random regression model. Gen. Sel. Evol. 30: $221-240$.

Meyer K (1998b). 'DXMRR' - A Program to Estimate Covariance Functions for Longitudinal Data by Restricted Maximum Likelihood. Proceedings of the 6th World Congress on Genetics Applied to Livestock Production, Armidale, 465-466.

Meyer K (1999). Estimates of genetic and phenotypic covariance functions for postweaning growth and mature weight of beef cows. J. Anim. Breed. Gen. 116: 181-205.

Meyer K (2000). Random regression to model phenotypic variation in monthly weights of Australian beef cows. Livest. Prod. Sci. 65: 19-38.

Meyer K and Hill WG (1997). Estimation of genetic and phenotypic covariance functions for longitudinal or "repeated" records by restricted maximum likelihood. Livest. Prod. Sci. 47: 185-200.

Meyer K, Carrick MJ and Donnelly BJ (1993). Genetic parameters for growth traits of Australian beef cattle from a multibreed selection experiment. J. Anim. Sci. 71:2614-2622.

Nephawe KA (2004). Application of random regression models to the genetic evaluation of cow weight in Bonsmara cattle of South Africa. S. Afr. J. Anim. Sci. 34: 166-173.

Nephawe KA, Maiwashe A and Theron HE (2006). The effect of herd of origin by year on post-weaning traits of young beef bulls at centralized testing centres in South Africa. S. Afr. Anim. Sci. 36: 33-39.

Schenkel FS, Miller SP, Jamrozik J and Wilton JW (2002). Two-step and random regression analyses of weight gain of station-tested beef bulls. J. Anim. Sci. 80: 1497-1507.

Schenkel FS, Miller SP and Wilton JW (2004). Herd of origin effect on weight gain of station-tested beef bulls. Livest. Prod. Sci. 86: 93-103.

Simm G, Smith C and Prescott JHD (1985). Environmental effects on bull performance test results. Anim. Prod. 41: 177-185.

Tong AKW, Newman JA and Rahnefeld GW (1986). Pretest herd effects on station performance test. Can. J. Anim. Sci. 66: 925-935. 